\title{
In vitro Antifungal Activity of a New Bioproduct Obtained from Grape Seed Proanthocyanidins on Botrytis cinerea Mycelium and Spores
}

\author{
Ancuța NECHITA ${ }^{1}$, Răzvan V. FILIMON ${ }^{1 *}$, Roxana M. FILIMON ${ }^{1}$, \\ Lucia-Cintia COLIBABA ${ }^{2}$, Daniela GHERGHEL ${ }^{3}$, Doina DAMIAN ${ }^{1}$, \\ Rodica PAȘA ${ }^{1}$, Valeriu V. COTEA ${ }^{2,4}$ \\ ${ }^{1}$ Research and Development Station for Viticulture and Winemaking Iași, 48 M. Sadoveanu Alley, 700489, Iasi, \\ Romania; ancuta.vasile@gmail.com; razvan_f80@yahoo.com (*correspondingauthor); roxanacotovanu@yahoo.com; \\ doinadamian@yahoo.com;pasarodica@yahoo.com \\ ${ }^{2}$ University of Agricultural Sciences and Veterinary Medicine, Faculty of Horticulture, 3 M. Sadoveanu Alley, 700490, Iasi, Romania; \\ cintia_colibaba@yahoo.co.uk;vcotea@uaiasi.ro \\ ${ }^{3}$ Institute of Biological Research, 47 Lascar Catargi Street, 700107, Iasi, Romania; daniela.gherghel@icbiasi.ro \\ ${ }^{4}$ Oenological Research Center of Romanian Academy - Iasi branch, 9 M. Sadoveanu Alley, 700490, Iasi, Romania
}

\begin{abstract}
Botrytis cinerea is a necrotrophic fungus that affects over 200 plant species. In vineyards, this pathogen is responsible for one of the most important diseases, commonly known as botrytis bunch rot or grey mould. Keeping infection under control with synthetic fungicides leads to an increased biological resistance of pathogen populations. An alternative way to synthetic products is to obtain natural fungicides by using bioactive compounds of plants. This study focuses on the antifungal properties of a new bioproduct obtained from polymeric proanthocyanidins extracted from grape seeds of 'Fetească neagră' variety. The bioproduct in solid state presented a total content of polyphenols of $0.625 \mathrm{mg} \mathrm{GAE} \mathrm{mg}^{-1}$, a polyphenolic index of 17.40 and an antioxidant activity of $91.27 \%$ scavenged DPPH. The bioproduct with polyphenolic structure showed a moderate effect on the radial growth of fungal mycelium, at $\mathrm{EC}_{50}$ values between 11.23 and $12.15 \mathrm{mg} \mathrm{mL}^{-1}$. Effective antifungal activity was showed in the inhibition of spore germination, where the $\mathrm{EC}_{50}$ values varied from 1.14 to $1.47 \mathrm{mg} \mathrm{mL}^{-1}$. These in vitro results sustain the possibility of including the bioproduct in the category of natural fungicides for biological control against Botrytis cinerea fungus.
\end{abstract}

Keywords: biological activity; minimum fungicidal concentration; natural fungicide; necrotrophic fungus; polyphenolic compounds

\section{Introduction}

In vineyards, among other pathogenic species, Botrytis cinerea Pers. is the most aggressive specie, causing significant economic damages (Gatto, 2011). Control of infection with Botrytis cinerea is currently performed with synthetic fungicides, but their danger has been proven, both for consumers and the environment due to the long time required for degradation (Lingk, 1991). Also, their frequent use in treatments promotes the emergence of resistant strains of Botrytis cinerea (Elad and Evensen, 1995). An alternative path to the chemical control of pathogenic fungi was outlined by focusing the research on bioactive components of plants, especially essential oils, to obtain extracts whose antifungal activity has been proven (Tripathi and Dubey, 2004, Lee et al., 2005; Tripathi et al., 2008; Sokovic et al., 2009; Wang et al., 2010; Vitoratos et al., 2013; Kocić-Tanackov et al., 2013; Seșan et al., 2015).

In plant defense system against pathogenic fungi, phenolic compounds are directly involved. These bioactive compounds are secondary metabolites synthesized by plants under stress conditions (i.e. injuries, infections, UV radiation), showing different chemical structures, from simple molecules (phenolic acids) to complex structures (i.e. flavanols, flavonols, anthocyanins, stilbens) (Ahmed et al., 2017). In grapes, phenolic compounds are found mainly in skins and seeds (Ky et al., 2012). In response to B. cinerea 
infection, phenolic phytoalexins are synthesized in grapes, mainly stilbens, with high antifungal activity (Goetz et al., 1999; Chong et al., 2009; Xu et al., 2018a).

In vitro antifungal activity of phenolic compounds on $B$. cinerea spore germination and mycelium growth has been extensively studied. Recent studies suggest that plant proanthocyanidins maintain $B$. cinerea in a quiescent stage, leading to delayed development of the symptoms (Van Baarlen et al., 2007). Moreover, plant proanthocyanidins may act as competitive inhibitors of $B$. cinerea laccase, thereby preventing detoxification of the phenolic phytoalexin (Goetz et al. 1999; Ky et al., 2012).

Mendoza et al. (2013) demonstrated in vitro inhibitory effect of polyphenols extracted from Cabernet Sauvignon grape pomace (skins and seeds) on $B$. cinerea mycelium growth and germ tube elongation. Tao et al. (2010) have evaluated in vitro six phenolic compounds for their antifungal activity and mode of action on $B$. cinerea. Catechin and quercetin-3-galactoside showed linear inhibitory effects on germ tube elongation, while gallic acid showed very strong and linear inhibition on spore germination, but the effect diminished after spore germination.

Patzke and Schieber (2008) used five phenolic compounds as active ingredients in the preparation of a bioactive emulsion and screened for their ability to inhibit the growth of phytopathogenic fungi. Ferulic acid was identified as highly effective against the growth of $B$. cinerea in very low concentrations $(0.085 \%)$.

Pathogen inhibition mechanisms vary depending on phenolic compounds tested, effective results can be obtained in the future by associating the ability of these compounds to inhibit both mycelium growth and spore germination.

Teixeira et al. (2014) highlighted the importance of phenolic compounds resulting as waste of winemaking industry, recommending their use in preparations with multiple biologically active properties. Grape seeds are a rich source of extractable phenolic compounds of which polymeric proanthocyanidins (PA) or condensed tannins, represent $75-81 \%$ of the total flavan-3-ols (Monagas et al., 2003). Our work aimed the recovery of this complex group of phenolic compounds from grape seeds of 'Fetească neagră' variety. As a result of the extraction procedures, was obtained a polyphenolic preparation in solid state, insoluble in water, but soluble in alcohol, with the yield of $30 \mathrm{~g} \mathrm{~kg}^{-1}$ dry weight. The phenolic structure of the preparation was determined by fractionation on $\mathrm{C} 18$ cartridges and thin layer chromatography (TLC), which allowed the identification and quantification of three fractions of proanthocyanidins: monomers (5.20 mg $100 \mathrm{~g}^{-1}$ d.w.), oligomers (11.05 mg $100 \mathrm{~g}^{-1}$ d.w.) and polymers (74.90 mg $100 \mathrm{~g}^{-1}$ d.w.) (Filimon et al., 2017). Vegetal waste resulting from extraction of phenolic compounds was used as organic fertilizer in soil (Nechita et al., 2017b).

The solid water-insoluble polyphenolic preparation was treated with hydrogen peroxide. After this treatment, polymers fragmentation resulted in a new water-soluble bioproduct with phenolic structure. The induction of water solubility properties allowed the evaluation of the antibacterial (Nechita et al., 2017a) and antitumoral activities of the new bioproduct.

The aim of this paper was to evaluate the in vitro antifungal activity of the water-soluble bioproduct obtained from grape seed proanthocyanidins, on the mycelial growth and spore germination of three $B$. cinerea strains.

\section{Materials and Methods}

\section{Plantmaterial}

Grape seeds resulting from the winemaking process of the 'Fetească neagră' grapes were manually extracted from the grape pomace, dried at room temperature, milled and defatted with n-hexane, in order to extract the phenolic compounds.

\section{Extraction of polymeric proanthocyanidins $(P A)$}

The extraction of polymeric PA was done with ethanol $96 \%$, in a solid:solvent ratio of $1: 4(\mathrm{w} / \mathrm{v})$, in three stages, at $30{ }^{\circ} \mathrm{C}$. The polyphenolic extracts were cumulated and concentrated in vacuum at $37^{\circ} \mathrm{C}$, up to a density of $1.0 \mathrm{~g}$ $\mathrm{cm}^{-3}$. Precipitation of polymeric PA was performed with $500 \mathrm{~mL}$ of $99 \%$ diethyl ether. The crude preparation of polymeric PA was soluble in $96 \%$ ethanol and insoluble in water. The induction of water solubility properties was conducted by the procedure proposed by Lupaşcu and Lupaşcu (2006), respectively, the treatment of the purified preparation of polymeric PA with $30 \%$ hydrogen peroxide under determined conditions: ratio preparation (PA) / oxidizing agent $1: 2.5(\mathrm{w} / \mathrm{w})$, temperature $67.5^{\circ} \mathrm{C}$, time of contact $45 \mathrm{~min}$, and removal of the oxidizing agent at $40{ }^{\circ} \mathrm{C}$ to constant weight. Obtained bioproduct was stored at $-18^{\circ} \mathrm{C}$ until assessing its biologically active properties.

For the characterization of the water-soluble bioproduct were determined its total polyphenolic content (TPC), polyphenolic index (PI) and antioxidant activity (AA).

Total polyphenolic content was analysed by FolinCiocalteu reagent, according to the protocol proposed by Singleton et al. (1999). Gallic acid was used as standard ( $\mathrm{y}=$ $\left.1.3243 x+0.0162 ; \mathrm{R}^{2}=0.9991\right)$, and the results were expressed as $\mathrm{mg}$ gallic acid equivalent (GAE) $\mathrm{mg}^{-1}$ bioproduct.

Polyphenolic index $\left(\mathrm{A}_{280}\right)$ was determined by measuring the absorption of phenol benzene cycles at $280 \mathrm{~nm}$, using a Shimadzu UV-VIS spectrophotometer (UV-VIS Mini Series 1240). Extracts were diluted $1 / 100$ and optical density (OD) was measured on a $10 \mathrm{~mm}$ optical path: $\mathrm{A}_{280}$ $=\mathrm{OD}_{280} \times$ dilution (Ribéreau-Gayon et al., 2006).

Antioxidant activity was determined according to the method proposed by Brand-William et al. (1995). Stock solution: $4.00 \mathrm{mg}$ of 2,2-diphenyl-1-picrylhydrazyl (DPPH) free radical in $100 \mathrm{~mL}$ of $96 \%$ ethanol. From the $1 \mathrm{mg} \mathrm{mL}^{-1}$ solution were taken $100 \mu \mathrm{L}$ to which $3.9 \mathrm{~mL}$ of DPPH solution was added. The control was obtained from $100 \mu \mathrm{L}$ of $96 \%$ ethanol and $3.9 \mathrm{~mL}$ of DPPH. The homogenized samples were incubated at $35{ }^{\circ} \mathrm{C}$ for 30 minutes. Absorbance of control samples and analysed samples were determined spectrophotometrically at $517 \mathrm{~nm}$. Antioxidant activity (AA) was calculated according to the formula: AA $=\left[\left(\mathrm{A}_{\text {control- }} \mathrm{A}_{\text {sample }}\right) / \mathrm{A}_{\text {control }}\right] \times 100$; where $\mathrm{A}$ represents the absorbances at $517 \mathrm{~nm}$. 
420

\section{HPLC procedure}

Characterization and quantification of individual polyphenolic compounds was conducted using the protocol presented by Castelari et al. (2002), by means of a Shimadzu LC-20 ultra-high-performance liquid chromatography system (UHPLC), coupled with a diode array detector (DAD) Shimadzu SPD-M30A. All samples were filtered through $0.45 \mu \mathrm{m}$ syringe filters. The chromatography precolumn used was a C18 Security Guard Ultra $4.6 \mathrm{~mm}$, coupled with a capillary C18 column Kinetex Phenomenex $2.6 \mu \mathrm{m}, 150 \times 4.6 \mathrm{~mm}$, thermostated at $20^{\circ} \mathrm{C}, 10 \mu \mathrm{L}$ of injection volume. Mobile phase $(\mathrm{pH} 2.15)$ was represented by $65 \mathrm{mM}$ TFA in $1 \%$ methanol as eluent $A$ and $65 \mathrm{mM}$ TFA in $50 \%$ methanol as eluent $\mathrm{B}$, with a flow rate of 0.85 $\mathrm{mL} / \mathrm{min}$. The HPLC gradient was performed as follows: $100 \%$ solvent A for the first $11 \mathrm{~min}, 82 \% \mathrm{~A} / 18 \% \mathrm{~B}$ from 11 to $19 \mathrm{~min}, 70 \% \mathrm{~A} / 30 \% \mathrm{~B}$ from 19 to $25 \mathrm{~min}, 65 \% \mathrm{~A} /$ $35 \%$ B from 25 to $33 \mathrm{~min}, 40 \% \mathrm{~A} / 60 \% \mathrm{~B}$ from 33 to 43 min, 20\% A / 80\% B from 43 to $46 \mathrm{~min}, 100 \%$ B from 46 to $53 \mathrm{~min}, 100 \%$ A from 53 to $60 \mathrm{~min}$. Detection was done at $280 \mathrm{~nm}$ based on spectral characteristics, while compounds quantification was performed by using pure external standards.

\section{In vitro evaluation of antifungal activity}

The antifungal activity of the bioproduct was determined in vitro by mycelial growth and spore germination inhibition. The assays were performed on three strains of Botrytis cinerea: $\mathrm{BC}_{5}, \mathrm{BC}_{6}$ and $\mathrm{BC}_{8}$, from the collection of microorganisms of Laboratory of Wine Microbiology belonging to the Research and Development Station for Viticulture and Winemaking Iasi, Romania.

The inhibition of mycelium radial development was performed in Petri dishes with potato dextrose agar (PDA) medium, containing different concentrations of bioproduct between 1 and $21 \mathrm{mg} \mathrm{mL}^{-1}$. For each $B$. cinerea strain, from the margins of the seven days old colonies, were collected 5 $\mathrm{mm}$ diameter mycelium discs and placed in the center of the Petri dishes with PDA medium supplemented with the bioproduct concentrations and at the center of the control plates with PDA medium without bioproduct. Three dishes were used for each test concentration. Petri dishes were incubated at $24{ }^{\circ} \mathrm{C}$ for five days. After this time, the diameter $(\mathrm{mm})$ of the colonies were measured in the control dishes and in the dishes supplemented with bioproduct. Inhibition (\%) of the radial development of the colonies was calculated according to the formula: $\mathrm{I} \%=[(\mathrm{dc}-\mathrm{dt}) / \mathrm{dc}] \times$ 100 , where: dc represents fungal diameter of the control and $\mathrm{dt}$ is the fungal diameter of the tested concentrations.

The spore suspension was obtained from PDA cultures of $B$. cinerea strains developed at room temperature, under fluorescent light, for 14 days (Richard et al., 2002). Preparation of the spore suspension was performed by introducing $20 \mathrm{~mL}$ of sterile distilled water containing 0.1 $\mathrm{mL} \mathrm{L}{ }^{-1}$ Tween 20 on the Petri dishes, and tender displacement of the spores with an inoculating loop. The spore suspension was filtered through four layers of sterile gauze to remove mycelial remains. In the spore germination inhibition test, was used a spore suspension of $10^{3}$ spores $\mathrm{mL}^{-1}$ numbered using a haemocytometer (Vitoratos et al., 2013). Thus, $0.1 \mathrm{~mL}$ of the $10^{3}$ spores $\mathrm{mL}^{-1}$ suspension roughly contained 100 spores that were placed on the surface of the PDA medium, in Petri dishes containing the bioproduct in concentrations of 1 to $12 \mathrm{mg} \mathrm{mL}^{-1}$. Three plates were used for each test concentration. All Petri dishes were incubated at $24^{\circ} \mathrm{C}$ until visible spore germination (48 h). The germinated spores were counted for each sample, as well as for the control.

Antifungal activity of the bioproduct was evaluated as minimum fungicidal concentration (MFC), determined as the lowest concentration of bioproduct that inhibited mycelial growth or spore germination, and as the effective concentrations that inhibits $50 \%$ of the mycelium growth or germinated spores $\left(\mathrm{EC}_{50}\right)$.

\section{Statistical procedures}

Data were reported as mean of minimum three replicates. Analysis of variance ANOVA test was initiated to investigate significant differences between strains. Tukey's test was used to discriminate among the means (XLStat software). Different letters indicate significant differences ( $\mathrm{p}$ $\leq 0.05)$. Regression analysis was performed to look for relationships between data.

\section{Results and Discussion}

\section{Bioproduct characterisation}

The physico-chemical characteristics of the phenolic bioproduct are showed in Table 1. The bioproduct, obtained through controlled oxidation of the waterinsoluble polymeric PA preparation appears as yellowbrown crusts, soluble in distilled water, with a total amount of polyphenolic compounds of $0.625 \mathrm{mg} \mathrm{GAE} \mathrm{mg}^{-1}$, with an antioxidant activity of $91.37 \%$ scavenged DPPH per $100 \mu \mathrm{g}$.

The UHPLC analysis highlighted a large number of signals represented by peaks of different amplitudes (Fig. 1). Based on the specific standards, were identified and quantified six phenolic compounds: gallic acid $(17.53 \mathrm{mg}$ $\left.\mathrm{g}^{-1}\right)$, protocatehuic acid $\left(5.29 \mathrm{mg} \mathrm{g}^{-1}\right)$, para-hydroxybenzoic acid $\left(0.89 \mathrm{mg} \mathrm{g}^{-1}\right)$, syringic acid $\left(4.09 \mathrm{mg} \mathrm{g}^{-1}\right)$, ferulic acid $\left(0.48 \mathrm{mg} \mathrm{g}^{-1}\right)$ and trans-resveratrol $\left(0.52 \mathrm{mg} \mathrm{g}^{-1}\right)$.

\section{Antifungal activity of the bioproduct on Botrytis cinerea mycelium growth}

Control colonies of $B$. cinerea strains showed different diameters on simple PDA medium: $8.56 \mathrm{~cm}$ for $\mathrm{BC}_{5}, 9.03$ $\mathrm{cm}$ for $\mathrm{BC}_{6}$ and $8.68 \mathrm{~cm}$ for $\mathrm{BC}_{8}$. Depending on the measured diameter for the control and each tested concentration of bioproduct, was calculated the mycelium growth inhibition (\%) for each fungal strain (Table 2).

Table 1. Physico-chemical characteristics of the phenolic bioproduct

\begin{tabular}{|c|c|c|c|c|c|c|}
\hline Bioproduct & $\begin{array}{l}\text { Physical } \\
\text { condition }\end{array}$ & Colour & Solubility in distilled water & 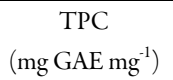 & $\begin{array}{c}\text { PI } \\
280 \mathrm{~nm}\end{array}$ & $\begin{array}{c}\mathrm{AA} \\
\left(\% \mathrm{DPPH}^{*}\right)\end{array}$ \\
\hline & solid & yellow - brown & completely & $0.63 \pm 0.08$ & $18.40 \pm 0.37$ & $91.37 \pm 0.68$ \\
\hline
\end{tabular}

Note: TPC: total polyphenolic content; PI: polyphenolic index; AA: antioxidant activity. 


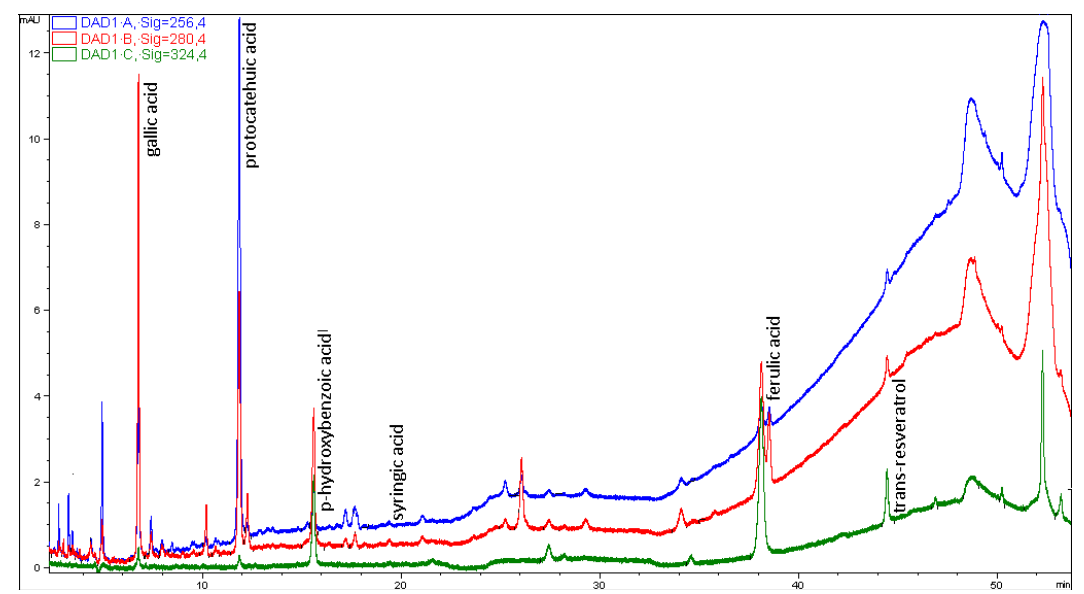

Fig. 1. HPLC chromatogram of the water-soluble bioproduct

Data analysis shows that the inhibition (\%) of mycelium growth increased progressively as the bioproduct concentration increased. Inhibition of mycelium growth, assessed by MFC, was determined at bioproduct concentrations between 18 and $21 \mathrm{mg} \mathrm{mL}^{-1}$. To determine the fungicidal spectrum, $\mathrm{EC}_{50}$ was calculated by linear regression. Coefficients of determination $\left(R^{2}\right)$, indicating the relationship between tested concentrations and the inhibition values, were high, due to a high degree of linearity between variables (see Table 2).

The sensitivity of $B$. cinerea strains to tested bioproduct was significantly different $(\mathrm{p} \leq 0.05)$. Thus, the half maximal effective concentration $\left(\mathrm{EC}_{50}\right)$ for mycelium growth of $\mathrm{BC}_{5}$ and $\mathrm{BC}_{6}$ strains was 11.23 and $11.66 \mathrm{mg} \mathrm{mL}^{-}$ ${ }^{P}$ respectively, while for $\mathrm{BC}_{8}$ strain the $\mathrm{EC}_{50}$ was $12.15 \mathrm{mg}$ $\mathrm{mL}^{-1}$.

During the experiment, the observations made on the morphology of $B$. cinerea mycelium indicated that the increasing of bioproduct concentrations resulted in the occurrence of larger degenerative areas (Fig. 2). This effect can be attributed to the presence of some phenolic compounds that affect the structure of the hyphae. Morphological changes of mycelial hyphae have been showed by Wang et al. (2010), by testing the antifungal activity of eugenol (2-methoxy-4-allylphenol), a compound with phenolic structure. In its presence, occurred various structural modifications of the hyphae, leading to the clotting of the cell cytoplasm, contraction of the hyphae and alteration of cytoplasmic membrane permeability.

In our experiment, the evaluation of the bioproduct activity on the radial growth of $B$. cinerea mycelium was performed by placing the mycelial inoculum on PDA medium with different concentrations of bioproduct (Fig. 3). Thus, by direct contact with the phenolic structure of the bioproduct, the enzyme complex synthesized in the mycelium favoured its development. The invasive manifestation of fungal mycelium at low concentrations, but blocked at higher concentrations of the bioproduct, allows the assessment of its antifungal activity as moderate, this assumption being supported by the data presented in the literature. During $B$. cinerea infection on grapes, the development of mycelium on the surface and inside the skin leads to direct contact between their constituents. Numerous studies have shown that hyphae of $B$. cinerea synthesizes laccases (EC 1.10.3.2), extracellular enzymes that catalyse the oxidation of phenolic compounds (Bollag and Leonowickz, 1984; Oszmianski et al., 1985; Pezet, 1998; Osman et al., 2007). Ky et al. (2012) evaluated the impact of $B$. cinerea infection on phenolic compounds concentration, in healthy and naturally or artificially infected grape skins, and found a severe decrease in phenolic compounds in infected grapes.

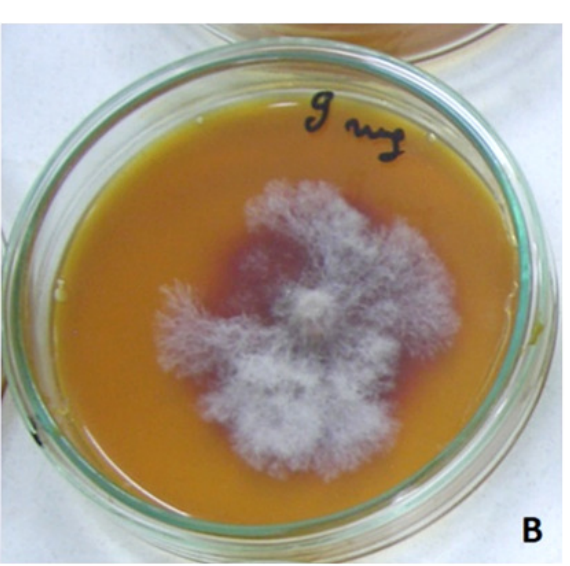

Fig. 2. Effect of the bioproduct on the development of Botrytis cinerea mycelium. Note: A: control (PDA medium); B: sample (PDA medium with bioproduct) 

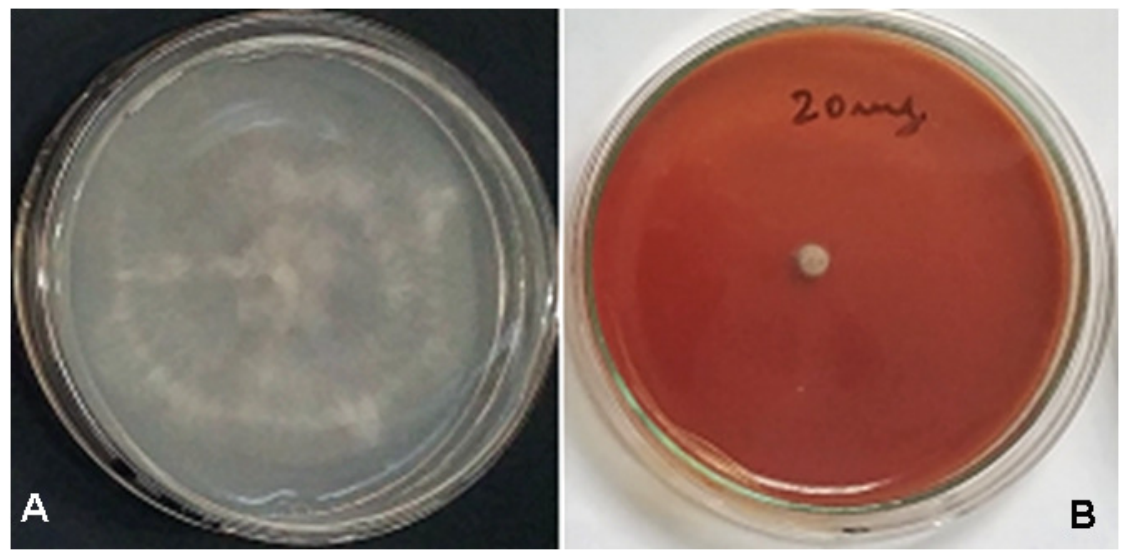

Fig. 3. Control (PDA medium) (A) and the concentration of bioproduct where the Botrytis cinerea mycelium growth was totally inhibited $\left(20 \mathrm{mg} \mathrm{mL}^{-1}\right)(B)$

Table 2. Biological activity of the bioproduct on Botrytis cinerea mycelium growth

\begin{tabular}{|c|c|c|c|c|c|c|c|}
\hline \multirow{2}{*}{$\begin{array}{c}\text { Bioproduct } \\
\text { concentration } \\
\left(\mathrm{mg} \mathrm{mL}^{-1}\right)\end{array}$} & \multicolumn{2}{|l|}{$\mathrm{BC}_{5}$} & \multicolumn{2}{|l|}{$\mathrm{BC}_{6}$} & \multicolumn{2}{|c|}{$\mathrm{BC} 8$} & \multirow[b]{2}{*}{ Significance } \\
\hline & Colony diameter $(\mathrm{cm})$ & Inhibition (\%) & Colony diameter $(\mathrm{cm})$ & Inhibition (\%) & $\begin{array}{l}\text { Colony diameter } \\
\qquad(\mathrm{cm})\end{array}$ & $\begin{array}{c}\text { Inhibition } \\
(\%)\end{array}$ & \\
\hline Control & $8.56^{\mathrm{a}}$ & 0.00 & $9.03^{\mathrm{a}}$ & 0.00 & $8.66^{\mathrm{a}}$ & 0.00 & *** \\
\hline 7 & $5.75^{b}$ & 0.00 & $6.80^{\mathrm{b}}$ & 0.00 & $5.85^{b}$ & 32.44 & $* * *$ \\
\hline 8 & $5.25^{b c}$ & 38.66 & $6.45^{b c}$ & 28.57 & $5.70^{b c}$ & 34.18 & *** \\
\hline 9 & $5.06^{\mathrm{bcd}}$ & 40.83 & $5.92^{\text {bcd }}$ & 34.44 & $5.45^{b c}$ & 37.06 & ** \\
\hline 10 & $4.74^{\mathrm{bcd}}$ & 44.58 & $5.23^{\text {cde }}$ & 42.10 & $5.26^{\mathrm{bcd}}$ & 39.22 & ** \\
\hline 11 & $4.47^{\text {cde }}$ & 47.75 & $4.87^{\mathrm{de}}$ & 46.09 & $4.91^{\text {bcde }}$ & 43.30 & $*$ \\
\hline 12 & $4.13^{\text {cde }}$ & 51.75 & $4.45^{\mathrm{ef}}$ & 50.75 & $4.65^{\text {cde }}$ & 46.34 & ** \\
\hline 13 & $3.87^{\text {def }}$ & 54.76 & $4.10^{\mathrm{efg}}$ & 54.62 & $4.25^{\text {def }}$ & 50.92 & ${ }^{* *}$ \\
\hline 14 & $3.53^{\text {efg }}$ & 58.76 & $3.38^{\mathrm{fgh}}$ & 62.62 & $3.81^{\mathrm{fgh}}$ & 56.03 & *** \\
\hline 15 & $2.90^{\mathrm{fgh}}$ & 66.12 & $2.83^{\text {ghi }}$ & 68.67 & $3.37^{\text {gh }}$ & 61.12 & ${ }^{* *}$ \\
\hline 16 & $2.50^{\mathrm{gh}}$ & 70.79 & $2.27^{\text {hij }}$ & 74.82 & $3.06^{\mathrm{hi}}$ & 64.70 & ${ }^{* * *}$ \\
\hline 17 & $2.17^{\mathrm{hi}}$ & 74.64 & $1.84^{\mathrm{ij}}$ & 79.64 & $2.59^{\mathrm{hi}}$ & 70.04 & $* * *$ \\
\hline 18 & $1.70^{\mathrm{hi}}$ & 80.14 & $0.92^{\mathrm{j}}$ & 89.85 & $2.25^{\mathrm{ij}}$ & 74.01 & *** \\
\hline 19 & $1.10^{\mathrm{ij}}$ & 87.14 & $0.00^{k}$ & 100.00 & $1.90^{\mathrm{k}}$ & 78.01 & $* * *$ \\
\hline 20 & $0.00^{j}$ & 100.00 & $0.00^{k}$ & 100.00 & $0.99^{\mathrm{j}}$ & 88.52 & $* *$ \\
\hline 21 & $0.00^{j}$ & 100.00 & $0.00^{k}$ & 100.00 & $0.00^{k}$ & 100.00 & $\mathrm{n} / \mathrm{s}$ \\
\hline LREq & \multicolumn{2}{|c|}{$y=4.6882 x-2.6667$} & \multicolumn{2}{|c|}{$y=6.0124 x-19.941$} & \multicolumn{2}{|c|}{$y=4.5358 x-5.1078$} & - \\
\hline $\mathrm{CD}$ & \multicolumn{2}{|c|}{0.9707} & \multicolumn{2}{|c|}{0.9888} & \multicolumn{2}{|c|}{0.9653} & - \\
\hline $\mathrm{EC}_{50}$ & \multicolumn{2}{|l|}{11.23} & \multicolumn{2}{|l|}{11.66} & \multicolumn{2}{|c|}{12.15} & - \\
\hline
\end{tabular}

Antifungal activity of the bioproduct on Botrytis cinerea spore germination

Spore germination of $\mathrm{BC}_{5}, \mathrm{BC}_{6}$ and $\mathrm{BC}_{8}$ strains started after 20 hours, in the case of control (PDA without bioproduct). In Petri dishes with PDA medium, where the tested concentrations of the bioproduct were introduced, the spore germination was visible after 48 hours. These findings suggest that the tested bioproduct is particularly active on the inhibition of spore germination, mainly due to the strong action of phenolic compounds on the growth and elongation of spore germ tube, as was previously reported by Nassr and Barakat (2013).

Depending on the number of germinated spores for the control and each bioproduct concentration (Fig. 4), the percentage of spore germination inhibition was calculated for each tested strain (Table 3 ).

In the antifungal activity test on $B$. cinerea spore germination was found that the number of germinated spores decreased progressively with the increase of the bioproduct concentrations. MFC values varied into small limits, inhibition of spore germination being performed at $10 \mathrm{mg} \mathrm{mL}^{-1}$ for $\mathrm{BC}_{5}$ and $\mathrm{BC} 6$ strains and $12 \mathrm{mg} \mathrm{mL}^{-1}$ for strain $\mathrm{BC}_{8}$. Also, the $\mathrm{EC}_{50}$ varied depending on the strain of $B$. cinerea used. Half maximal effective concentration $\left(\mathrm{EC}_{50}\right)$ of bioproduct on spore germination was achieved at concentrations of $1.18 \mathrm{mg} \mathrm{mL}^{-1}$ for $\mathrm{BC}_{5}, 1.26 \mathrm{mg} \mathrm{mL}^{-1}$ for $\mathrm{BC}_{6}$ and $1.42 \mathrm{mg} \mathrm{mL}^{-1}$ for $\mathrm{BC}_{8}$ strain, confirming a superior resistance of $\mathrm{BC}_{8}$ strain to bioproduct action (see Table 3). 
Table 3. Biological activity of the bioproduct on Botrytis cinerea spore germination

\begin{tabular}{|c|c|c|c|c|c|c|c|}
\hline \multirow{2}{*}{$\begin{array}{l}\text { Bioproduct } \\
\text { concentration } \\
\left(\mathrm{mg} \mathrm{mL}^{-1}\right)\end{array}$} & \multicolumn{2}{|l|}{$\mathrm{BC}_{5}$} & \multicolumn{2}{|c|}{$\mathrm{BC}_{6}$} & \multicolumn{2}{|c|}{$\mathrm{BC}_{8}$} & \multirow{2}{*}{ Significance } \\
\hline & Germinated spores & Inhibition (\%) & Germinated spores & Inhibition (\%) & Germinated spores & Inhibition (\%) & \\
\hline Control & $115^{a}$ & 0.00 & $110^{a}$ & 0.00 & $125^{a}$ & 0.00 & $* *$ \\
\hline 1 & $71^{b}$ & 38.26 & $69^{b}$ & 37.27 & $82^{\mathrm{b}}$ & 34.40 & *** \\
\hline 2 & $51^{c}$ & 55.65 & $53^{c}$ & 51.82 & $62^{c}$ & 50.40 & ${ }^{* *}$ \\
\hline 3 & $42^{\mathrm{cd}}$ & 63.48 & $39^{\mathrm{cd}}$ & 64.55 & $48^{\mathrm{cd}}$ & 61.60 & $* * *$ \\
\hline 4 & $30^{\text {de }}$ & 73.91 & $28^{\mathrm{de}}$ & 74.55 & $38^{\mathrm{de}}$ & 69.60 & ${ }^{* *}$ \\
\hline 5 & $24^{\mathrm{ef}}$ & 79.13 & $20^{\text {ef }}$ & 81.82 & $32^{\mathrm{ef}}$ & 74.40 & ${ }^{* *}$ \\
\hline 6 & $17^{\mathrm{fg}}$ & 85.22 & $12^{\mathrm{fg}}$ & 89.09 & $25^{\mathrm{efg}}$ & 80.00 & ${ }^{* * *}$ \\
\hline 7 & $10^{\text {gh }}$ & 91.30 & $9^{\mathrm{fg}}$ & 91.82 & $18^{\text {fgh }}$ & 85.60 & ${ }^{* * *}$ \\
\hline 8 & $5^{\mathrm{h}}$ & 95.65 & $4^{\mathrm{h}}$ & 96.36 & $11^{\text {ghi }}$ & 91.20 & ${ }^{* * *}$ \\
\hline 9 & $2^{\text {hi }}$ & 98.26 & $1^{\text {hi }}$ & 99.09 & $8^{\text {hi }}$ & 93.60 & ${ }^{* * *}$ \\
\hline 10 & $0^{\mathrm{i}}$ & 100.00 & $0^{\mathrm{i}}$ & 100.00 & $4^{\mathrm{hi}}$ & 96.80 & ** \\
\hline 11 & $0^{\mathrm{i}}$ & 100.00 & $0^{\mathrm{i}}$ & 100.00 & $2^{\mathrm{i}}$ & 98.40 & $\mathrm{n} / \mathrm{s}$ \\
\hline 12 & $0^{\mathrm{i}}$ & 100.00 & $0^{\mathrm{i}}$ & 100.00 & $0^{\mathrm{i}}$ & 100.00 & $\mathrm{n} / \mathrm{s}$ \\
\hline LREq & \multicolumn{2}{|c|}{$y=6.5033 x+42.319$} & \multicolumn{2}{|c|}{$y=6.7493 x+41.515$} & \multicolumn{2}{|c|}{$y=5.5015 x+42.182$} & - \\
\hline $\mathrm{COF}$ & \multicolumn{2}{|c|}{0.9323} & \multicolumn{2}{|c|}{0.9105} & \multicolumn{2}{|c|}{0.9145} & - \\
\hline $\mathrm{EC}_{50}$ & \multicolumn{2}{|l|}{1.18} & \multicolumn{2}{|c|}{1.26} & \multicolumn{2}{|c|}{1.42} & - \\
\hline
\end{tabular}
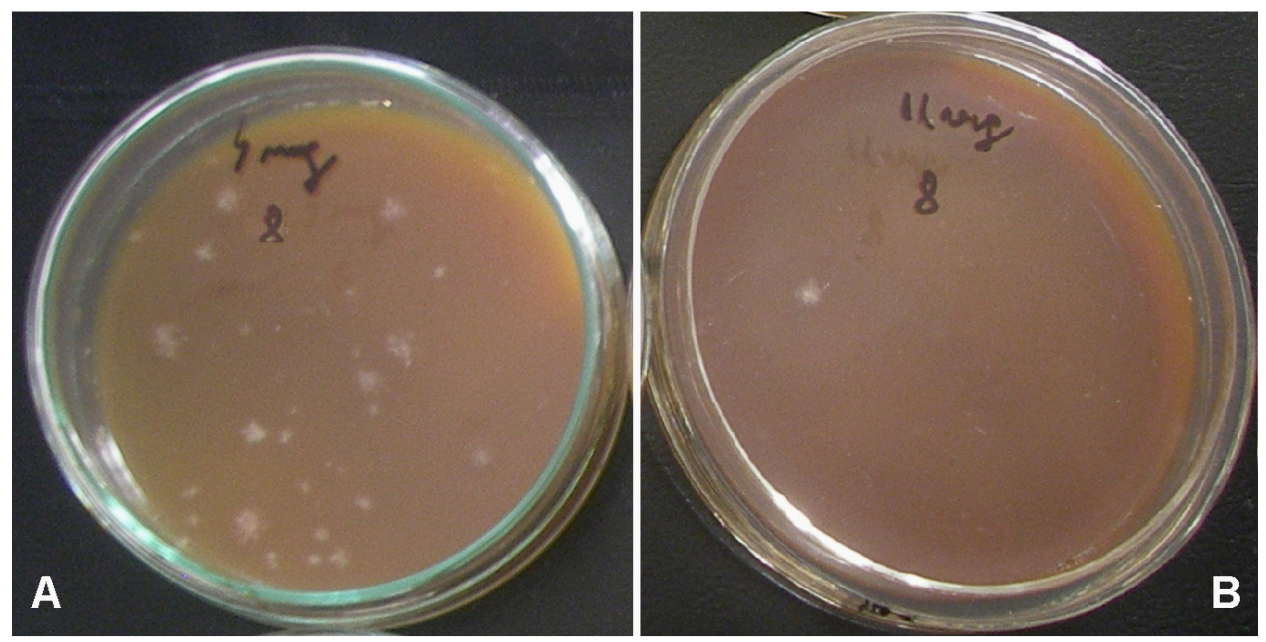

Fig. 4. Botrytis cinerea spores germination at low concentrations of bioproduct (A) and at minimum fungicidal concentration (B)

The coefficients of determination $\left(\mathrm{R}^{2}\right)$, obtained by correlating the bioproduct concentrations and the values for spore germination inhibition, were high $(0.9323,0.9105$ and 0.9145 ), due to a high degree of linearity between variables.

Fourie and Holz (2001) studied the antifungal activity of the synthetic product Folpet, on a number of $71 B$. cinerea strains. The authors showed a different manifestation of the synthetic product on mycelium and spores, the $\mathrm{EC}_{50}$ values for the inhibition of spore germination were significantly lower than those obtained in the inhibition of mycelium growth. This aspect was also showed in the present study, when the new phenolic bioproduct obtained from grape seeds was tested for its antifungal activity.

Increasing the antifungal potential of bioproduct against B. cinerea may be possible through a synergistic effect, achieved by its interaction with plant extracts, whose antifungal potential has been proven, or synthetic fungicides. A recent approach in this regard was performed by Xu et al. (2018b). 
424

\section{Conclusions}

Polymeric proanthocyanidins extracted from grape seeds can be used as a biologically active product after inducing the water-solubilisation properties by oxidative treatment with hydrogen peroxide. Biological activity of the phenolic bioproduct on Botrytis cinerea mycelium growth was manifested at moderate MFC values, between 18 and $21 \mathrm{mg}$ $\mathrm{mL}^{-1}$. However, inhibition of spore germination was achieved at concentrations approximately ten times lower than those obtained for the mycelium growth inhibition, between 1.14 and $1.47 \mathrm{mg} \mathrm{mL}^{-1}$, results that justify the possibility of using the phenolic bioproduct as potential natural agent for the biological control of Botrytis cinerea, as an alternative to currently used synthetic products that pose a risk to human health and the environment.

\section{Acknowledgements}

This work was supported by MEN-UEFISCDI, project no. 183/2014 (PN-II-PT-PCCA-2013-4-0333) "Technology of capitalization of the bioactive elements from the grape seed waste with usefulness in the food and pharmaceutical industry, plant and environmental protection (Acronym: PROVITIS)".

\section{References}

Ahmed E, Arshad M, Khan MZ, Amjad MS, Sadaf HM, Riaz I, Sabir S, Ahmad N, Sabaoon (2017). Secondary metabolites and their multidimensional prospective in plant life. Journal of Pharmacognosy and Phytochemistry 6(2):205-214.

Bollag JM, Leonowickz A (1984). Comparative studies of extracellular fungal laccases. Applied Environmental Microbiology 48:849-854.

Brand-Williams W, Cuvelier M, Berset C (1995). Use of free radical method to evaluate antioxidant activity. LWT-Food Science and Technology 28(1):25-30.

Castellari M, Sartini E, Fabiani A, Arfelli G, Amati A (2002). Analysis of wine phenolics by high-performance liquid chromatography using a monolithic type column. Journal of Chromatography 973(1-2):221227.

Chong J, Poutaraud A, Hugueney P (2009). Metabolism and roles of stilbenes in plants. Plant Science 177:143-155.

Elad Y, Evensen K (1995). Physiological aspects of resistance to Botrytis cinerea. Phytopathology 85:637-643.

Filimon VR, Nechita A, Damian D, Paşa R, Filimon R, Băetu M, MihaiCT, Niculaua M (2017). Separation and characterisation of the main proanthocyanidin fractions of grape seeds. Lucrări Ştiințifice USAMV Iaşi, Seria Horticultură60(1):69-74.

Fourie PH, Holz G (2001). Incomplete cross-resistance to folpet and iprodione in Botrytis cinerea from grapevine in South Africa. South African Journal of Enology and Viticulture 22:3-7.

Gatto MA, Ippolito A, Linsalata V, Cascarano NA, Nigro F, Vanadia S, Di Venere D (2011). Activity of extracts from wild edible herbs against postharvest fungal diseases of fruit and vegetables. Postharvest Biology \& Technology61:72-82.
Goetz G, Fkyerat A, Métais N, Kunz M, Tabacchi R, Pezet R, Pont V (1999). Resistance factors to grey mould in grape berries: identification of some phenolics inhibitors of Botrytis cinerea stilbene oxidase. Phytochemistry 52:759-767.

Kocić-Tanackov SD, Dimić GR (2013). Antifungal activity of essential oils in the control of food-borne fungi growth and myco-toxin biosynthesis in food. In:Mendez-Vilas A(Ed). Microbial pathogens and strategies for combating them. Science, technology and education pp. 838-849.

Ky I, Lorrain B, Jourdes M, Pasquier G, Fermaud M, Gény L, Rey P, Doneche B, Teissedre PL (2012). Assessment of grey mould (Botrytis cinerea) impact on phenolic and sensory quality of Bordeaux grapes, musts and wines for two consecutive vintages. Australian Journal of Grape and Wine Research 18:215-226.

Lee HC, Cheng SS, Chang ST (2005). Antifungal property of the essential oils and their constituents from Cinnamomum osmophloeum leaf against tree pathogenic fungi. Journal of the Science of Food and Agriculture 85:2047-2053.

Lingk W (1991). Health risk evaluation of pesticide contamination in drinkingwater. Gesunde Pflangen 43:21-25.

Lupașcu T, Lupașcu L (2006). Procedeu de obținere a enotaninurilor hidrosolubile [Process for obtaining water-soluble enotanins]. Patent no. MD 3125 F1 2006.08.31. State Agency on Intellectual Property, Republic of Moldova. Retrieved 2016 February 18 from http://www.db.agepi.md/inventions/results.

Mendoza L, Cotoras M, Vivanco M, Matsuhiro B, Torres S, Aguirre M (2013). Evaluation of antifungal properties against the phytopathogenic fungus Botrytis cinerea of anthocyanin rich-extracts obtained from grape pomaces. Journal of the Chilean Chemical Society 58(2):1725-1727.

Monagas M, Gómez-Cordovés C, Bartolomé B, Laureano O, Da Silva JR (2003). Monomeric, oligomeric, and polymeric flavan-3-ol composition of wines and grapes from Vitis vinifera L. cv. Graciano, Tempranillo, and Cabernet Sauvignon. Journal of Agricultural and Food Chemistry 51:6475-6481.

Nassr S, Barakat R (2013). Effect of factors on conidium germination of Botrytis cinerea in vitro. International Journal of Plant and Soil Science 2(1):41-54.

Nechita A, Alexandru C, Filimon VR, Filimon R, Damian D, Nechita B, Pașa R (2017a). Antimicrobial activity of an active biological bioproduct obtained from grape seeds. Lucrări Ştiințifice USAMV Iaşi, Seria Horticultură 60(1):91-96.

Nechita A, Filimon R, Zaldea G, Filimon VR, Damian D, Nechita B, Pașa R (2017b). Valuation of vegetal residue of grape seeds resulting from the extractive processes of phenolic compounds. Lucrări Ştiinţifice USAMV Iaşi, Seria Horticultură60(1):85-90.

Osman AM, Wong KKY, Fernyhough A (2007). The laccase/ABTS system oxidizes (+)-catechin to oligomeric products. Enzyme and Microbial Technology 40(5):1272-1279.

Oszmianski J, Sapis JC, Macheix JJ (1985). Changes in grape seed phenols as affected by enzymatic and chemical oxidation in vitro. Journal of Food Science 50:1505-1506.

Patzke H, Schieber A (2018). Growth-inhibitory activity of phenolic compounds applied in an emulsifiable concentrate - ferulic acid as a natural pesticide against Botrytis cinerea. Food Research International 
113:18-23.

Pezet R (1998). Purification and characterization of a $32 \mathrm{KDa}$ laccase-like stilbene oxidase produced by Botrytis cinerea Pers. Fr. FEMS. Microbiology Letters 167:203-208.

Ribéreau-Gayon P, Glories Y, Maujean A, Dubourdieu D (2006). Handbook of Enology. Vol. 2. The Chemistry of Wine. Stabilization and Treatments (2nded.).John Wiley \& Sons Ltd, Chichester.

Richard AS, Eileen PR, David HY (2002). Novel fungitoxicity assays for inhibition of germination-associated adhesion of Botrytis cinerea and Puccinia recondita spores. Applied and Environmental Microbiology 68:597-601.

Seșan TE, Enache E, Iacomi BM, Oprea M, Oancea F, Iacomi C (2015). Antifungal activity of some plant extract against Botrytis cinerea Pers. in the blackcurrant crop (Ribes nigrum L.). Acta Scientiarum Polonorum, Hortorum Cultus 14:29-43.

Singleton VL, Orthofer R, Lamuela-Raventos RM (1999). Analysis of total phenols and other oxidation substrates and antioxidants by means of Folin-Ciocalteu reagent. Methods in Enzymology 299:152-178.

Sokovíc MD, Vukojevíc J, Marin PD, Brkíc DD, Vajs V, Van Griensven LJLD (2009). Chemical composition of essential oils of Thymus and Mentha species and their antifungal activities. Molecules 14:238-249.

Tao S, ZhangS, Tsao R, Charles MT, Yang R, Khanizadeh S (2010). In vitro antifungal activity and mode of action of selected polyphenolic antioxidants on Botrytis cinerea. Archives of Phytopathology and Plant Protection 43(16):1564-1578.

Teixeira A, Baenas N, Dominguez-Perles R, Barros A, Rosa E, Moreno DA, Garcia-Viguera C (2014). Natural bioactive compounds from winery by-products as health promoters: a review. International Journal of MolecularSciences 15:15638-15678.
Tripathi P, Dubey NK (2004). Exploitation of natural products as alternative strategy to control postharvest fungal rotting of fruits and vegetables. Postharvest Biology and Technology 32:235-245.

Tripathi P,Dubey NK, Shukla AK (2008). Use of some essential oils as postharvest botanical fungicides in the management of grey mould of grapes caused by Botrytis cinerea. World Journal of Microbiology \& Biotechnology 24:39-46.

van Baarlen P, Legendre L, van Kan JAL (2007). Plant defence compounds against Botrytis infection. In: Elad Y, Williamson B, Tudzynski P, Delen N (Eds). Botrytis: Biology, Pathology and Control. Springer, Dordrecht pp 143-161.

Vitoratos A, Bilalis D, Karkanis A, Efthimiadou A (2013). Antifungal activity of plant essential oils against Botrytis cinerea, Penicillium italicum and Penicillium digitatum. Notulae Botanicae Horti Agrobotanici ClujNapoca41(1):86-92.

Wang C, Zhang J, Chen H, Fan Y, Shi Z (2010). Antifungal activity of eugenol against Botrytis cinerea. Tropical Plant Pathology 35 (3):137143.

Xu D, Deng Y, Han T, Jiang L, Xi P, Wang Q, Jiang Z, Gao L (2018a). In vitro and in vivo effectiveness of phenolic compounds for the control of postharvest gray mold of table grapes. Postharvest Biology and Technology 139:106-114.

Xu D, Yu G, Xi P, Kong X, Wang Q, Gao L, Jiang Z (2018b). Synergistic effects of resveratrol and pyrimethanil against Botrytis cinerea on grape. Molecules 23(6):1455. 